\title{
Cold blood cardioplegia reduces the increase in cardiac enzyme levels compared with cold crystalloid cardioplegia in patients undergoing aortic valve replacement for isolated aortic stenosis
}

\author{
Bjørn Braathen, MD, and Theis Tønnessen, MD, $\mathrm{PhD}$
}

\begin{abstract}
Objectives: Cardiac arrest during cardiac surgery is most commonly induced by cold blood or cold crystalloid cardioplegia. The results from clinical studies are divergent regarding which of the 2 solutions provides better myocardial protection. This might be explained by several factors. Both heterogeneity in disease for the included patients and the fact that most studies are retrospective in design and that patients with coronary artery disease with different degrees of myocardial ischemia are included might explain these findings. To circumvent these potentially confounding factors, we included in a prospective randomized study only patients undergoing aortic valve replacement for aortic stenosis without other significant cardiac disease. Patients were randomized to antegrade cold crystalloid or cold blood cardioplegia.
\end{abstract}

\begin{abstract}
Methods: Eighty patients with aortic stenosis undergoing aortic valve replacement without significant coronary artery stenosis or other significant concomitant heart valve disease were included in the study. They were randomized to either antegrade cold blood or cold crystalloid cardioplegic solution delivered through the coronary ostia every 20 minutes throughout the period of aortic crossclamping. Maximum postoperative creatine kinase isoenzyme MB and troponin-T levels, well-established markers of myocardial damage, were compared between the 2 groups.
\end{abstract}

Results: Both maximum postoperative creatine kinase isoenzyme MB and troponin-T levels were significantly higher by approximately $100 \%$ in the cohort of patients receiving crystalloid compared with blood cardioplegia. Only in the group of patients receiving cold crystalloid cardioplegia was there a positive correlation between cardiac enzyme levels and crossclamp time.

Conclusion: Antegrade cold blood cardioplegia provides better myocardial protection than cold crystalloid cardioplegia in patients undergoing aortic valve replacement. (J Thorac Cardiovasc Surg 2010;139:874-80)

Over the past decades, the question of which cardioplegic solution provides better myocardial protection during cardiac surgery has been widely debated. Experimental studies have suggested a favorable outcome ${ }^{1-4}$ for blood cardioplegia compared with crystalloid cardioplegia. Surprisingly, however, clinical studies have not been conclusive regarding which type of cardioplegia provides better protection. ${ }^{5,6}$ There are several possible reasons for this. First, in the majority of published studies, the groups of patients included are heterogeneous with regard to a number of factors, such as cause (ie, coronary artery disease, valvular disease, and others), surgical procedure performed, and crossclamp

From the Department of Cardiothoracic Surgery, Ullevål University Hospital, University of Oslo, and Center for Heart Failure Research, Oslo, Norway.

Supported by the Ingegerd and Viking Olov Björk Scholarship received by Dr Tønnessen.

Disclosures: None.

Received for publication March 16, 2009; revisions received April 26, 2009; accepted for publication May 31, 2009; available ahead of print July 27, 2009

Address for reprints: Theis Tønnessen, MD, PhD, Department of Cardiothoracic Surgery, Ullevål University Hospital, and University of Oslo, Oslo, Norway (E-mail: thto@uus.no).

0022-5223/\$36.00

Copyright (c) 2010 by The American Association for Thoracic Surgery doi:10.1016/j.jtcvs.2009.05.036 time, possibly masking potential differences. ${ }^{5,6}$ A second explanation might be that the crossclamp times in some studies are too short to demonstrate a difference that might unmask itself with longer crossclamp times. ${ }^{7}$ A third explanation might be that the chosen end points (eg, mortality and hospital stay) are not discriminating well between the differences in protection. Moreover, various degrees of coronary artery stenosis in the included patients might also mask a potential difference because a prerequisite for comparing 2 cardioplegic solutions is that they reach the myocardium to the same degree. Differences in the temperature of the solutions, the composition of the different cardioplegic solutions, and the means of application might also contribute to difficulties in interpreting the results. To circumvent these possible confounding factors, we decided to choose a homogeneous group of patients with potentially similar crossclamp times and without coronary artery disease. Thus only patients with lone aortic stenosis were included in the present study. The left ventricular hypertrophy in these patients also makes their hearts vulnerable to ischemia, which, theoretically, should make it easier to detect a potential difference in cardiac protection between the 2 solutions.

Thus the aim of the present study was to examine the effects of 2 of the most frequently used cardioplegic solutions, 


\section{Abbreviations and Acronyms \\ $\mathrm{CK}-\mathrm{MB}=$ creatine kinase isoenzyme MB \\ $\mathrm{ECG}=$ electrocardiography}

antegrade cold blood and antegrade cold crystalloid cardioplegia, on myocardial damage in patients with isolated aortic stenosis undergoing aortic valve replacement. According to statistical calculations before the start of the study, 80 patients were randomized to one of the 2 cardioplegic solutions. Cardioplegia was performed under standardized conditions, and creatine kinase isoenzyme MB (CK-MB) and troponin-T levels, well-established markers of myocardial damage, were used as indicators of myocardial damage.

\section{MATERIALS AND METHODS}

\section{Study Population and Design}

From November 2006 to February 2009, 80 consecutive patients undergoing elective aortic valve replacement at Ullevål University Hospital, Oslo, Norway, volunteered to participate and were included in the study. All patients provided written consent. The local ethics committee approved the study protocol. Eligible for operation were patients with a mean aortic valve gradient of greater than $50 \mathrm{~mm} \mathrm{Hg}$ or an aortic valve area of less than $0.7 \mathrm{~cm}^{2}$ or symptomatic aortic valve stenosis. Before induction of anesthesia, on the same day as the operation, patients were randomly allocated to one of 2 groups, either receiving cold $\left(4^{\circ} \mathrm{C}-8^{\circ} \mathrm{C}\right)$ crystalloid or cold $\left(4^{\circ} \mathrm{C}-8^{\circ} \mathrm{C}\right)$ blood cardioplegic solution. The randomization was performed by opening sealed envelopes, and every cohort of 10 patients was block randomized (5 to crystalloid and 5 to blood cardioplegia) to ensure an even distribution of the 2 regimens with time.

Although cardioplegic solution is frequently administered in a retrograde manner through the coronary sinus, this procedure might provide an inadequate protection of the right ventricle unless combined with antegrade administration of cardioplegic solution through the right coronary ostium. For the sake of simplicity, in the present study cardioplegic solution was delivered in an antegrade fashion only through the coronary ostia strictly every 20 minutes with a pressure of $300 \mathrm{~mm} \mathrm{Hg}$ or less with a Stöckert roller pump (Stöckert Instrumente GmbH, Munich, Germany) throughout the period of aortic crossclamping. Initially, $400 \mathrm{~mL}$ of cardioplegic solution was administrated immediately after asystole. Every 20 minutes, 300 to $400 \mathrm{~mL}$ was administrated into the left coronary ostium and 200 to $300 \mathrm{~mL}$ into the right coronary ostium, taking the size of the heart into consideration.

Patients with significant coronary artery stenoses $(\geq 50 \%)$ or other significant concomitant heart valve disease were excluded from the study. Ten patients were also excluded from the study after randomization (5 patients in each group) for the following reasons. In the group receiving blood cardioplegia, 4 patients were excluded because they needed additional cardioplegia (because of emergence of spontaneous heart rhythm after 10-12 minutes) before that scheduled by the protocol. One patient was excluded because the heart did not stop and the surgeon decided to open the aorta and administer cardioplegic solution directly into the coronary ostia. In the group receiving crystalloid cardioplegia, 2 patients were excluded because they needed additional cardioplegia (because of emergence of spontaneous heart rhythm after 10-13 minutes) before that scheduled by the protocol. Two patients were excluded because the heart did not stop initially and the surgeon decided to open the aorta and administer cardioplegic solution directly into the coronary ostia. One patient was excluded because the second shot of cardioplegic solution was administered 30 minutes after the first (and not 20 minutes, as decided by the protocol).

\section{Anesthesia and Operative Technique}

Patients underwent operations as previously described. ${ }^{8}$ Anesthesia was induced with diazepam $(0.1-0.2 \mathrm{mg} / \mathrm{kg})$, fentanyl (3-5 $\mu \mathrm{g} / \mathrm{kg})$, thiopental $(0.5-$ $2.0 \mathrm{mg} / \mathrm{kg})$, and cisatracurium $(0.15 \mathrm{mg} / \mathrm{kg})$ and maintained with sevoflurane ( $1 \%$ to $2 \%$ inspired). Midazolam $(0.02-0.04 \mathrm{mg} / \mathrm{kg})$ and fentanyl $(1-2 \mu \mathrm{g} / \mathrm{kg})$ were administered in addition to sevoflurane during cardiopulmonary bypass. Anticoagulation was accomplished with systemic heparinization $(4 \mathrm{mg} / \mathrm{kg}$ body weight) and supplemented as required to maintain an activated clotting time of greater than 480 seconds. All operations were performed by using the standard technique of cardiopulmonary bypass with extracorporeal circulation with a Stöckert roller pump, ascending aortic cannulation, single venous cannulation, and moderate systemic hypothermia $\left(32^{\circ} \mathrm{C}\right)$.

\section{Myocardial Protection}

One of the following 2 cardioplegic solutions was used for myocardial protection.

Crystalloid cardioplegia. We used a modified St Thomas II cardioplegic solution. One liter of crystalloid cardioplegic solution contains the following components: potassium, $19.6 \mathrm{mmol} / \mathrm{L}$; magnesium, $16.7 \mathrm{mmol} /$ $\mathrm{L}$; calcium, $2.0 \mathrm{mmol} / \mathrm{L}$; sodium, $128.0 \mathrm{mmol} / \mathrm{L}$; procaine hydrochloride, $1.0 \mathrm{mmol} / \mathrm{L}$; acetate, $29.4 \mathrm{mmol} / \mathrm{L}$, and chloride $157.8 \mathrm{mmol} / \mathrm{L}(\mathrm{pH} 6.3$; temperature, $4^{\circ} \mathrm{C}-8^{\circ} \mathrm{C}$ ).

Blood cardioplegia. One liter of blood cardioplegic solution contains the following components: potassium, $21.5 \mathrm{mmol} / \mathrm{L}$; magnesium, $18.2 \mathrm{mmol} / \mathrm{L}$; calcium, $2.2 \mathrm{mmol} / \mathrm{L}$; sodium, $145.1 \mathrm{mmol} / \mathrm{L}$; procaine hydrochloride, $1.1 \mathrm{mmol} / \mathrm{L}$; acetate, $6.5 \mathrm{mmol} / \mathrm{L}$; chloride, $154.9 \mathrm{mmol} / \mathrm{L}$; and hydrogen carbonate, $28.9 \mathrm{mmol} / \mathrm{L}\left(\mathrm{pH} 7.4\right.$; temperature, $\left.4^{\circ} \mathrm{C}-8^{\circ} \mathrm{C}\right)$.

\section{Use of Inotropic Support and Postarrest Recovery Time}

We measured the time from release of the aortic crossclamp until weaning from extracorporeal circulation and registered the use of inotropic infusions for longer than 20 minutes in the first 24 postoperative hours.

\section{Registration of Postoperative Atrial Fibrillation}

A 12-lead electrocardiogram (ECG) was recorded daily on the first 3 postoperative days and compared with the ECG before surgical intervention. All patients were also monitored with telemetry continuously for the 3 first postoperative days. Patients who had 1 or more episodes of atrial fibrillation postoperatively without a history of atrial fibrillation preoperatively were registered.

\section{Measurements of Cardiac Marker Proteins}

We collected venous blood samples before the operation and 7, 20, 44, and 68 hours postoperatively. The time points were chosen because of the profile of the enzyme release in plasma after myocardial ischemia. ${ }^{9}$ CK-MB and troponin-T levels were immediately analyzed in the Department of Clinical Chemistry at Ullevål University Hospital, as previously described. ${ }^{10}$ The serum cardiac troponin-T level was determined by using an electrochemiluminescence immunoassay on the Roche Elecsys 2010 immunoassay analyzer (Roche Diagnostics, Mannheim, Germany). The upper normal reference limit (99th percentile) is less than $0.10 \mathrm{ng} / \mathrm{mL}$. The serum CK-MB level was determined by using an electrochemiluminescence immunoassay on the Roche Elecsys 2010 immunoassay analyzer. The upper normal reference limit (99th percentile) is less than $5 \mathrm{ng} / \mathrm{mL}$.

\section{Criteria for Perioperative Myocardial Infarction}

According to guidelines set by our department, 2 of the 3 following criteria had to be fulfilled: (1) CK-MB level of $100 \mu \mathrm{g} / \mathrm{L}$ or greater, troponin-T level of $3.0 \mu \mathrm{g} / \mathrm{L}$ or greater, or both; (2) development of a new Q-wave on an ECG of more than 0.03 seconds postoperatively; and (3) development of 
a new hypokinetic or akinetic area in the left or right ventricle, as determined by means of echocardiographic analysis.

\section{Statistical Analysis}

Data are presented as means \pm standard error of the mean. They were analyzed with SigmaStat, version 3.1 (Jandel Scientific GmbH, Erkrath, Germany). A 50\% difference between groups regarding markers of myocardial damage was considered significant to calculate sample size. Based on the results from a previous study, ${ }^{8}$ our study with 80 patients would result in a power of 0.99 with a $P$ value of .05 . Differences between the 2 groups were analyzed by using the Student's $t$ test or the Mann-Whitney rank sum test for data normally or not normally distributed, respectively. Differences within groups over time were analyzed by using analysis of variance for repeated measures and corrected for multiple comparisons. Data not normally distributed were transformed by means of natural logarithm to fit a normal distribution when examining the relation between 2 continuous variables by means of linear regression. Comparisons of groups with dichotomous data were analyzed by using the Fisher's exact test or the $\chi^{2}$ test. $P<.05$ was considered as statistically significant.

\section{RESULTS}

Patient characteristics are shown in Table 1. We did not find any significant differences regarding any of the variables presented in the table. There was no 30-day mortality in either of the groups. There were no differences in the frequency of atrial fibrillation, time from weaning from extracorporeal circulation, inotropic support, or myocardial infarction in the 2 groups.

\section{CK-MB}

There were approximately $100 \%$ higher maximum CK-MB levels in the group of patients receiving cold crystalloid cardioplegia (Figure 1) compared with those receiving cold blood cardioplegia $(56.1 \pm 13.9$ and $29.3 \pm 1.5 \mu \mathrm{g} / \mathrm{L}$, respectively). The highest levels were found 7 hours after the operation (Figure 2). Three patients in the study population had postoperative CK-MB levels of greater than $100 \mu \mathrm{g} / \mathrm{L}$, which is suspicious of a perioperative myocardial infarction. All of these patients received cold crystalloid cardioplegia. However, none of these patients showed other signs of myocardial infarction on echocardiographic or ECG analysis and were thus not classified as having myocardial infarction according to our criteria. In Figure 3 the maximum CK-MB level is plotted against crossclamp time in the 2 groups. This figure shows that in patients receiving cold blood cardioplegia, there was no correlation between maximum CK-MB level and crossclamp time at up to 2 hours of crossclamping. In the group receiving cold crystalloid cardioplegia, however, there was a significant correlation between maximum CK-MB level and crossclamp time $(R=0.42, P=.01)$. There was no correlation between CK-MB levels and the amount of cardioplegic solution administered in either group.

\section{Troponin-T}

As with $\mathrm{CK}-\mathrm{MB}$, the maximum troponin-T level was approximately $100 \%$ higher in the group of patients receiv-
TABLE 1. Patient characteristics

\begin{tabular}{|c|c|c|c|}
\hline Characteristics & $\begin{array}{c}\text { Blood } \\
\text { cardioplegia* }\end{array}$ & $\begin{array}{c}\text { Crystalloid } \\
\text { cardioplegia* }\end{array}$ & $P$ value \\
\hline Age (y) & $68.2 \pm 2.0$ & $71.3 \pm 1.5$ & .21 \\
\hline Female sex (no.) & 18 & 14 & .47 \\
\hline $\begin{array}{l}\text { Extracorporeal } \\
\quad \text { circulation (min) }\end{array}$ & $103.6 \pm 3.6$ & $105.8 \pm 3.1$ & .64 \\
\hline Crossclamp time (min) & $74.4 \pm 3.6$ & $75.6 \pm 3.1$ & .80 \\
\hline $\begin{array}{l}\text { Postarrest recovery } \\
\quad(\min )\end{array}$ & $23.1 \pm 1.1$ & $24.1 \pm 1.1$ & .53 \\
\hline $\begin{array}{l}\text { Preoperative } \\
\quad \text { creatinine }(\mu \mathrm{mol} / \mathrm{L})\end{array}$ & $83.1 \pm 3.8$ & $79.9 \pm 3.3$ & .53 \\
\hline $\begin{array}{l}\text { Postoperative } \\
\quad \text { creatinine }(\mu \mathrm{mol} / \mathrm{L})\end{array}$ & $82.5 \pm 5.3$ & $80.3 \pm 4.4$ & .76 \\
\hline $\begin{array}{l}\text { Postoperative } \\
\text { inotropic } \\
\text { infusion (no.) }\end{array}$ & 1 & 1 & 1.00 \\
\hline Postoperative AF (no.) & 13 & 15 & .81 \\
\hline 30-d Mortality (no.) & 0 & 0 & \\
\hline IVSd (cm) & $1.3 \pm 0.03$ & $1.3 \pm 0.05$ & .52 \\
\hline $\begin{array}{l}\text { Myocardial infarction } \\
\text { (no.) }\end{array}$ & 0 & 0 & \\
\hline Preoperative EF & $51 \%$ & $51 \%$ & .24 \\
\hline $\begin{array}{l}\text { Preoperative use of } \\
\beta \text {-blockers }\end{array}$ & $29 \%$ & $34 \%$ & .80 \\
\hline $\begin{array}{l}\text { Postoperative use of } \\
\beta \text {-blockers }\end{array}$ & $82 \%$ & $82 \%$ & 1.00 \\
\hline $\begin{array}{l}\text { Defibrillation after } \\
\text { crossclamp removal } \\
\text { (no.) }\end{array}$ & 2 & 1 & 1.00 \\
\hline $\begin{array}{l}\text { Amounts of } \\
\text { cardioplegia }(\mathrm{mL})\end{array}$ & $2195.7 \pm 106.5$ & $2018.6 \pm 64.3$ & .26 \\
\hline $\begin{array}{l}\text { Lowest core } \\
\text { temperature under } \\
\text { Extracorporeal } \\
\text { Circulation }\left({ }^{\circ} \mathrm{C}\right) \\
\end{array}$ & $32.7 \pm 0.1$ & $32.7 \pm 0.1$ & 1.00 \\
\hline
\end{tabular}

ing cold crystalloid cardioplegia compared with that seen in the patients receiving cold blood cardioplegia $(1.21 \pm 0.37$ and $0.58 \pm 0.05 \mu \mathrm{g} / \mathrm{L}$, respectively). Troponin- $\mathrm{T}$ was not detectable before the operation and showed the highest levels in the first postoperative set of blood samples and decreased levels in the following 3 sets (Figure 2). There was a significant correlation between maximum troponin- $T$ level and crossclamp time (Figure 3 ) only in the group of patients receiving cold crystalloid cardioplegia $(R=0.37, P=.03)$. There was no correlation between troponin-T levels and the amount of cardioplegic solution administered in either group.

\section{DISCUSSION}

The present prospective randomized study demonstrates clearly that markers of myocardial damage were 

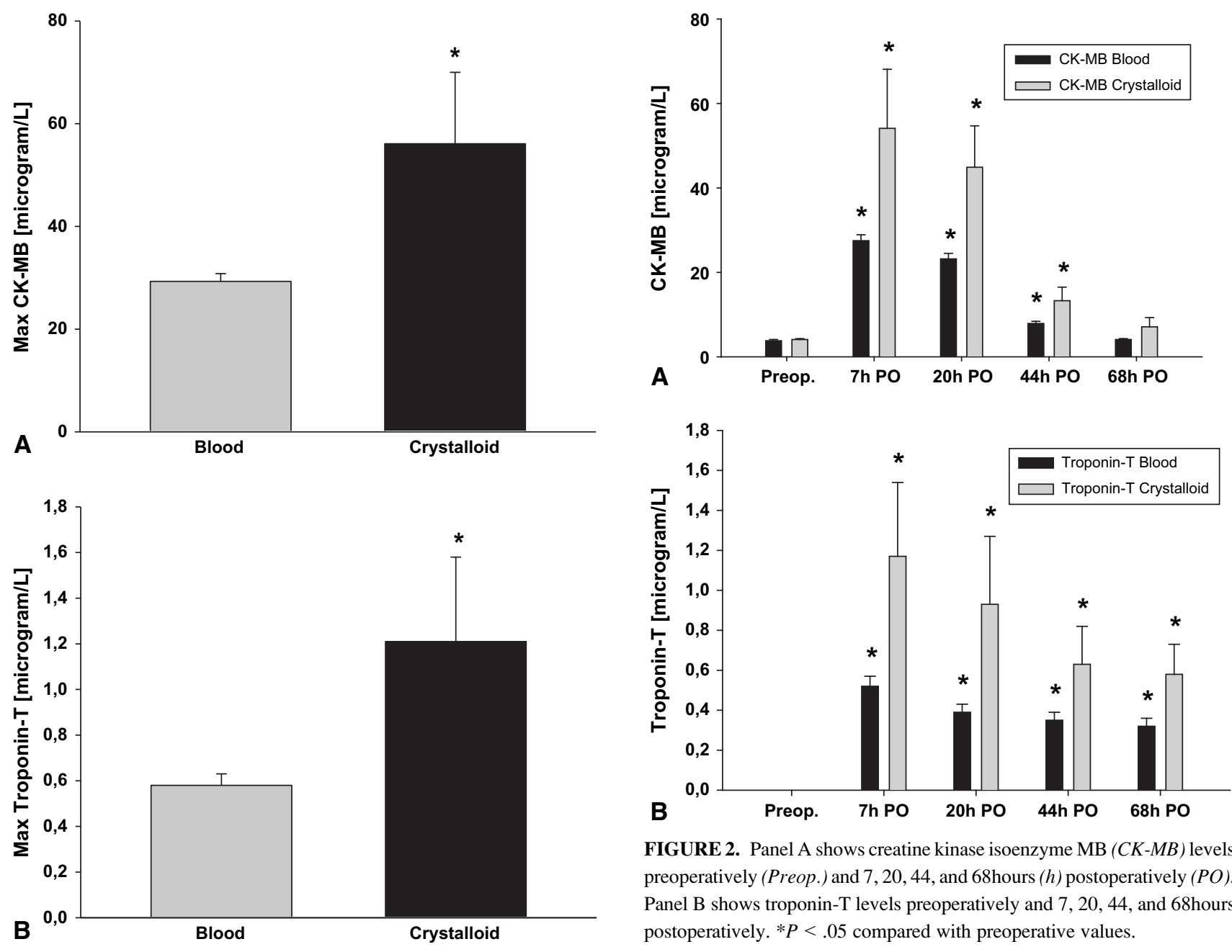

FIGURE 2. Panel A shows creatine kinase isoenzyme MB (CK-MB) levels preoperatively (Preop.) and 7, 20, 44, and 68hours $(h)$ postoperatively $(P O)$. Panel B shows troponin-T levels preoperatively and 7, 20, 44, and 68hours postoperatively. $* P<.05$ compared with preoperative values.

FIGURE 1. Panel A shows maximum (Max) postoperative creatine kinase isoenzyme MB $(C K-M B)$ levels with blood and crystalloid cardioplegia. Panel B shows maximum postoperative troponin-T levels with blood and crystalloid cardioplegia. $* P<.05$ compared with blood cardioplegia.

significantly lower in patients undergoing operations for aortic stenosis who were randomized to cold blood cardioplegia compared with those receiving cold crystalloid cardioplegia. Moreover, we found a positive correlation between cardiac enzyme levels and crossclamp time only in the group of patients receiving cold crystalloid cardioplegia. No difference in the frequency of atrial fibrillation, inotropic support, myocardial infarction, or mortality was detected between groups.

Experimental studies ${ }^{1-4}$ have reported a favorable effect of blood cardioplegia over crystalloid cardioplegia in inducing cardiac arrest. The results from clinical studies have been less convincing. ${ }^{5,6}$ The reasons for this might be many. Several studies are retrospective in design with historical data, ${ }^{11-14}$ and many studies also include patients with a wide range of cardiac pathologies, surgical procedures, and crossclamp times. ${ }^{5,6}$ This might mask a potential difference in end points between blood and crystalloid cardiople-

gia. Moreover, almost all published studies include patients with coronary artery disease of various degrees, ${ }^{5,6}$ and coronary artery stenoses might in turn result in an uneven distribution of cardioplegia within the myocardium and thus increase the variation of protection and measured end points and mask a potential effect. In one well-performed, large, prospective randomized study by Øvrum and coworkers, ${ }^{7}$ no difference in clinical outcome was detected between blood and crystalloid cardioplegia in patients undergoing coronary artery bypass grafting surgery. In that study, however, mean crossclamp time was only 34 minutes, and this might be too short to demonstrate a potential difference. Markers of myocardial damage were also not given in that study. Although a few clinical studies have reported a favorable effect of blood cardioplegia, ${ }^{15-18}$ others have not been able to demonstrate any difference, ${ }^{7,19-22}$ and in some a worse outcome for patients receiving cold blood cardioplegia has been reported. ${ }^{23}$

In our opinion the optimal group of patients to demonstrate a potential benefit for blood over crystalloid cardioplegia would be patients undergoing cardiac surgery with 

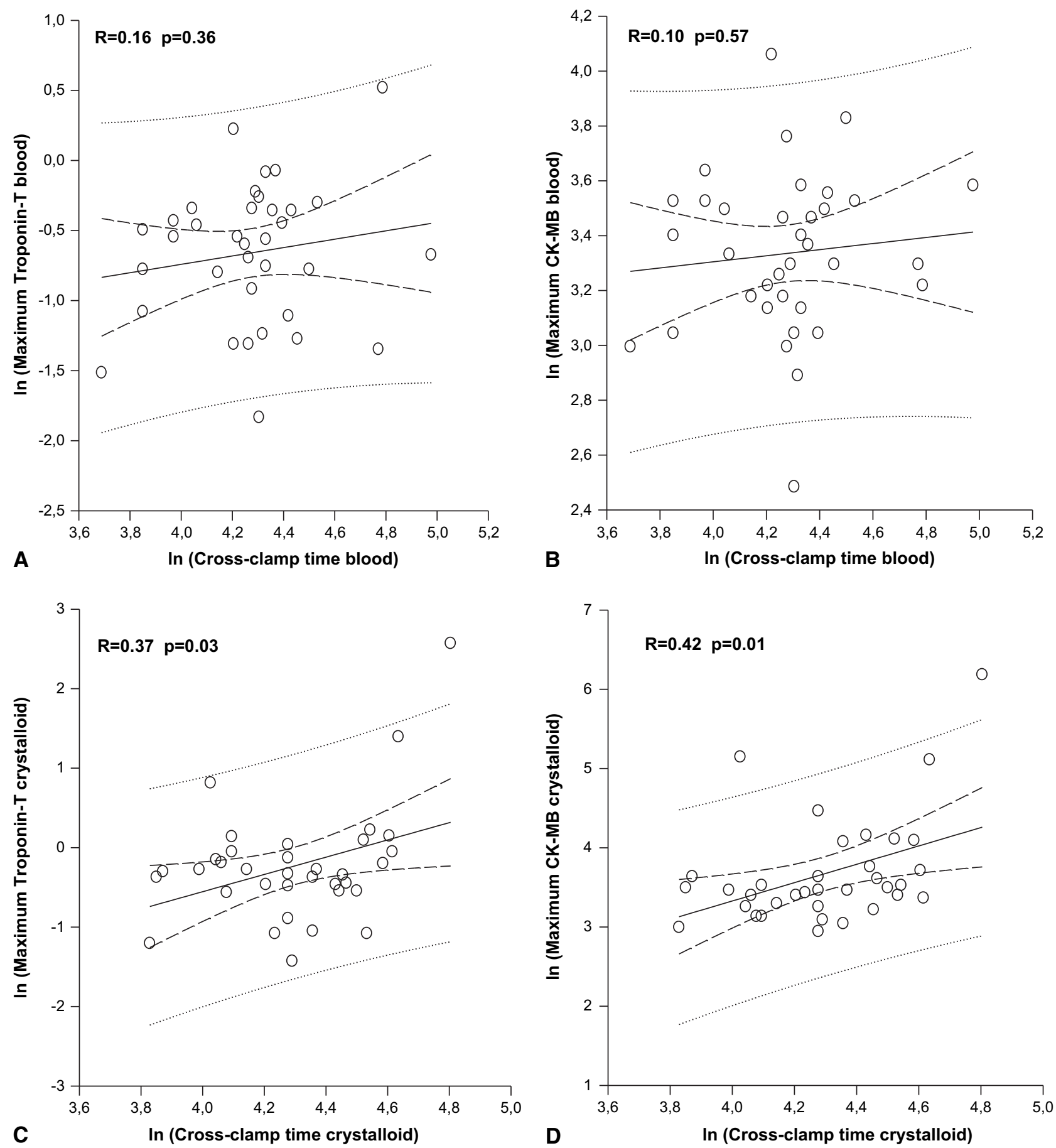

FIGURE 3. Panels A and B show no correlation between cardiac enzyme levels and crossclamp times in the group of patients receiving cold blood cardioplegia. Panels $\mathrm{C}$ and D show a positive correlation between cardiac enzyme levels and crossclamp times in the group of patients receiving cold crystalloid cardioplegia. Dashed lines show 95\% confidence and prediction intervals. Max, Maximal; $C K-M B$, creatine kinase isoenzyme MB.

relatively long crossclamp times, with no compromised coronary flow to ensure the full effect of the cardioplegic solution, and with a disease susceptible to ischemia. Therefore patients undergoing aortic valve replacement with no coronary artery disease would be ideal to test the hypothesis that cold blood cardioplegia provides better protection of the myocardium than cold crystalloid cardioplegia. This is a fairly homogenous group of patients with approximate expected crossclamp times of about 75 minutes in our department, and the myocardial hypertrophy makes the heart 
susceptible to ischemia, which would make it easier to detect a possible difference between groups. Surprisingly, we have only been able to find 1 prospective randomized study comparing cold blood and cold crystalloid cardioplegia in patients undergoing aortic stenosis without coronary artery disease. In that study by Bouchart and colleagues, ${ }^{23}$ cold blood cardioplegia resulted in higher levels of CK-MB compared with cold crystalloid cardioplegia, which is contrary to expectations. The study did not provide any answer for this unexpected finding. However, no power analysis was presented in the study, and they compared statistically 3 groups of only 20 patients, which makes a type I statistical error (ie, a false-positive result) possible. In another study by Jin and associates,${ }^{24}$ antegrade and retrograde cold blood cardioplegia resulted in better preservation of myocardial physiologic response and less inotropic support. However, this study included a mixed group of patients in which more than a third of the patients received concomitant coronary artery bypass grafting. Furthermore, CK-MB levels, troponin-T levels, or other markers of myocardial damage were not measured. We think it is important to measure markers of myocardial damage because these most likely would discriminate better between beneficial effects than clinical outcome. The ability to detect differences in hard clinical end points, such as mortality, often requires a much larger number of patients in each group than presented in most published studies. It should be noted that none of our patients died within 30 days of surgical intervention, and according to our criteria, none had a perioperative myocardial infarction.

In the present study patients receiving cold crystalloid cardioplegia had approximately double the circulating levels of CK-MB and troponin-T than patients receiving cold blood cardioplegia, indicating greater myocardial damage. Another interesting finding was the significant positive correlation between crossclamp time up to 2 hours and cardiac enzyme levels in patients receiving cold crystalloid cardioplegia only. The $R^{2}$ values were 0.14 and 0.18 for troponin-T and CK-MB, respectively, suggesting that $14 \%$ and $18 \%$ of the increase in enzyme levels is explained by the crossclamp time. Because there was no significant correlation between crossclamp time and markers of myocardial damage in the group receiving cold blood cardioplegia in the same time span, this suggests, together with the lower release of troponin-T and CK-MB, that cold blood cardioplegia provides better cardioprotection than crystalloid cardioplegia in patients undergoing aortic valve replacement. Of course, it could be argued that clinical differences and not enzyme levels of myocardial damage are the most important end points when comparing 2 regimens of cardioplegia. Nevertheless, we think that the clearly lower enzyme levels in the group receiving cold blood cardioplegia advocate for this cardioplegic regimen in high-risk patients or patients undergoing complex surgical procedures. It should also be noted that Nesher and colleagues ${ }^{25}$ have shown a correlation between troponin- $T$ levels after cardiac surgery and a composite end point of death, electrocardiographically defined infarction, and low output syndrome (major adverse cardiac events). Furthermore, Lehrke and coworkers ${ }^{26}$ reported a significant correlation between troponin-T levels postoperatively and long-term survival after cardiac surgery.

The exact mechanism for the lower enzyme release in the blood cardioplegia group was not examined in the present study. The differences in concentrations of electrolytes between the 2 cardioplegic solutions might contribute to this finding. Moreover, delivery of oxygenated blood to the cardiomyocytes, a more effective buffer system, and a better and more uniform capillary flow have also been suggested as mechanisms behind a better protection with blood cardioplegia. $^{2}$

In the present study we could not demonstrate any significant differences in atrial fibrillation, use of inotropic support, and postarrest recovery time in the 2 cardioplegia groups. These findings are in accordance with those of previously published studies. ${ }^{7,21}$ However, it should be noted that our study was not designed to answer these questions and might thus be underpowered.

\section{Study Limitations}

This study has some limitations. First, the surgeons were not blind to which type of cardioplegia was being used. Moreover, the power calculations were made to ensure a high enough power regarding comparisons of postoperative cardiac enzyme release. With regard to clinical end points, however, there might be too few patients to rule out a type II statistical error.

\section{CONCLUSION}

For the first time, we have, in patients undergoing operations for isolated aortic stenosis, demonstrated in a prospective randomized study that markers of myocardial damage are significantly lower in patients randomized to cold blood cardioplegia compared with those receiving cold crystalloid cardioplegia. We also found a positive correlation between cardiac enzyme levels and crossclamp time only in the group of patients receiving cold crystalloid cardioplegia.

We thank the staff of the Department of Cardiothoracic Surgery and the Department of Cardiothoracic Anesthesiology, Ullevål University Hospital, for helping to perform the study. We also thank Ståle Nygård for valuable advice regarding statistical analyses.

\section{References}

1. Axford-Gatley RA, Wilson GJ, Feindel CM. Comparison of blood-based and asanguineous cardioplegic solutions administered at 4 degrees C. An ultrastructural morphometric study in the dog. J Thorac Cardiovasc Surg. 1990;100:400-9.

2. Barner HB. Blood cardioplegia: a review and comparison with crystalloid cardioplegia. Ann Thorac Surg. 1991;52:1354-67. 
3. Catinella FP, Cunningham JN Jr, Spencer FC. Myocardial protection during prolonged aortic cross-clamping. Comparison of blood and crystalloid cardioplegia. J Thorac Cardiovasc Surg. 1984;88:411-23.

4. Feindel CM, Tait GA, Wilson GJ, Klement P, MacGregor DC. Multidose blood versus crystalloid cardioplegia. Comparison by quantitative assessment of irreversible myocardial injury. J Thorac Cardiovasc Surg. 1984;87:585-95.

5. Guru V, Omura J, Alghamdi AA, Weisel R, Fremes SE. Is blood superior to crystalloid cardioplegia? A meta-analysis of randomized clinical trials. Circulation. 2006;114(suppl):I331-8.

6. Jacob S, Kallikourdis A, Sellke F, Dunning J. Is blood cardioplegia superior to crystalloid cardioplegia? Interact Cardiovasc Thorac Surg. 2008;7:491-8.

7. Ovrum E, Tangen G, Tollofsrud S, Oystese R, Ringdal MA, Istad R. Cold blood cardioplegia versus cold crystalloid cardioplegia: a prospective randomized study of 1440 patients undergoing coronary artery bypass grafting. $J$ Thorac Cardiovasc Surg. 2004;128:860-5.

8. Braathen B, Vengen OA, Tonnessen T. Myocardial cooling with ice-slush provides no cardioprotective effects in aortic valve replacement. Scand Cardiovasc J. 2006;40:368-73.

9. Jaffe AS, Babuin L, Apple FS. Biomarkers in acute cardiac disease: the present and the future. J Am Coll Cardiol. 2006;48:1-11.

10. Larstorp AC, Lund SC, Tonnessen T, Muller C, Kjeldsen SE, Mangschau A. Scintigraphic demonstration of myocardial perfusion and ischaemia associated with coronary artery bypass grafting. Scand Cardiovasc J. 2006;40:354-62.

11. Calafiore AM, Teodori G, Di GG, Bosco G, Mezzetti A, Lapenna D, et al. Intermittent antegrade cardioplegia: warm blood vs cold crystalloid. A clinical study. J Cardiovasc Surg (Torino). 1994;35:179-84

12. Daggett WM Jr, Randolph JD, Jacobs M, O'Keefe DD, Geffin GA, Swinski LA, et al. The superiority of cold oxygenated dilute blood cardioplegia. Ann Thorac Surg. 1987;43:397-402.

13. Kaul TK, al KR, Sharif H, Ramsdale DR. Results of combined valve replacement and myocardial revascularization. Relation to method of myocardial protection. J Cardiovasc Surg (Torino). 1989;30:322-7.

14. Loop FD, Higgins TL, Panda R, Pearce G, Estafanous FG. Myocardial protection during cardiac operations. Decreased morbidity and lower cost with blood cardioplegia and coronary sinus perfusion. J Thorac Cardiovasc Surg. 1992;104: 608-18.

15. Brat R, Tosovsky J, Januska J, Derych L, Velkoborsky S, Bruk V, et al. Comparison between blood and crystalloid cardioplegia in patients with left ventricular dysfunction undergoing coronary surgery. Acta Medica (Hradec Kralove). 2000;43:107-10.

16. Christakis GT, Fremes SE, Weisel RD, Madonik MM, McDonough JH, Tittley JG, et al. Reducing the risk of urgent revascularization for unstable angina: a randomized clinical trial. J Vasc Surg. 1986;3:764-72.

17. Fremes SE, Christakis GT, Weisel RD, Mickle DA, Madonik MM, Ivanov J, et al. A clinical trial of blood and crystalloid cardioplegia. J Thorac Cardiovasc Surg. 1984;88:726-41.

18. Ibrahim MF, Venn GE, Young CP, Chambers DJ. A clinical comparative study between crystalloid and blood-based St Thomas' hospital cardioplegic solution. Eur J Cardiothorac Surg. 1999;15:75-83.

19. Caputo M, Dihmis W, Birdi I, Reeves B, Suleiman MS, Angelini GD, et al. Cardiac troponin $\mathrm{T}$ and troponin I release during coronary artery surgery using cold crystalloid and cold blood cardioplegia. Eur J Cardiothorac Surg. 1997;12: 254-60.

20. Hendrikx M, Jiang H, Gutermann H, Toelsie J, Renard D, Briers A, et al. Release of cardiac troponin I in antegrade crystalloid versus cold blood cardioplegia. J Thorac Cardiovasc Surg. 1999;118:452-9.

21. Martin TD, Craver JM, Gott JP, Weintraub WS, Ramsay J, Mora CT, et al. Prospective, randomized trial of retrograde warm blood cardioplegia: myocardial benefit and neurologic threat. Ann Thorac Surg. 1994;57:298-302.

22. Young JN, Choy IO, Silva NK, Obayashi DY, Barkan HE. Antegrade cold blood cardioplegia is not demonstrably advantageous over cold crystalloid cardioplegia in surgery for congenital heart disease. J Thorac Cardiovasc Surg. 1997;114: 1002-8.

23. Bouchart F, Bessou JP, Tabley A, Hecketsweiller B, Mouton-Schleifer D, Redonnet M, et al. How to protect hypertrophied myocardium? A prospective clinical trial of three preservation techniques. Int J Artif Organs. 1997;20: 345-51.

24. Jin XY, Gibson DG, Pepper JR. Early changes in regional and global left ventricular function after aortic valve replacement. Comparison of crystalloid, cold blood, and warm blood cardioplegias. Circulation. 1995;92(suppl):II155-62.

25. Nesher N, Alghamdi AA, Singh SK, Sever JY, Christakis GT, Goldman BS, et al. Troponin after cardiac surgery: a predictor or a phenomenon? Ann Thorac Surg. 2008;85:1348-54

26. Lehrke S, Steen H, Sievers HH, Peters H, Opitz A, Muller-Bardorff M, et al. Cardiac troponin $\mathrm{T}$ for prediction of short- and long-term morbidity and mortality after elective open heart surgery. Clin Chem. 2004;50:1560-7. 